\title{
Changes in Antioxidant Enzymes Activity and Oxidative Damage in Four Argania spinosa Ecotypes Under Water Stress Conditions
}

\author{
Abdelghani CHAKHCHAR ${ }^{1,2,3}$ (chakhchar.ckr@gmail.com), Abderrahim FERRADOUS ${ }^{3}$, \\ Mounia LAMAOUI ${ }^{1,2}$, Said. WAHBI ${ }^{2}$ \& Cherkaoui EL MODAFAR ${ }^{1}$ \\ ${ }^{1}$ Laboratory of Biotechnology Valorisation and Protection of Agro-Ressources, Faculty of Sciences and \\ Technology Gueliz, 40000 Marrakech. Morocco. \\ ${ }^{2}$ Laboratory of Biotechnology and Plant Physiology, Faculty of Sciences Semlalia, 40000 Marrakech. \\ Morocco. \\ ${ }^{3}$ Regional Forestry Research Centre in Marrakech. BP 12360 Ennakhil Ain Itti Marrakech. Morocco.
}

Argania spinosa L. Skell, a tree endemic of Morocco, grows in semiarid and arid areas. Biochemical response to drought in four ecotypes of the A. spinosa was compared. Choice of ecotypes was based on evident differences in geographical features in south-west Morocco: two coastal ecotypes (Essaouira and Agadir) and two paralittorale ecotypes (Aoulouz and Lakhssas). Lipid peroxidation (malonyldialdehyde (MDA)), content of endogenous hydrogen peroxide (H2O2) and antioxidant enzyme system (Catalase (CAT), Ascorbate peroxidase (APX), Total peroxidase (POD) and Polyphenoloxidase (PPO) were measured in control $(100 \%$ relative humidity $(\mathrm{RH})$ at field capacity (FC)) and water-stressed plants (50 and $25 \%$ $\mathrm{RH}$ at FC). For all ecotypes, drought stress significantly increased the contents of MDA and $\mathrm{H} 2 \mathrm{O} 2$ and an ecotype effect was noted. According Two-way ANOVA analysis, the ecotype $\mathrm{x}$ watering regime interaction was highly significant. We found an increase in the activities of the four ROS-scavenging enzymes and an ecotype effect was noted. Ecotype $\mathrm{x}$ watering regime interaction shows that only the CAT and APX activities were significant. Highest values of POD and PPO activities were found in both paralittorale ecotypes. Increase in antioxidant enzyme activities appears to be an adaptive response to restore the reactive oxygen species in their homeostasis. The four study ecotypes were separated by two discriminant functions obtained by canonical discriminant analysis. Coastal ecotypes are separated from the paralittorale ecotypes mainly by POD and PPO activities and MDA content.

Keywords: Argania spinosa; Drought stress; Antioxidant enzyme system; Oxydative damage 